\title{
Robust control of a multi-bus DC microgrid based on adaptive Lyapunov function method
}

\author{
Mohammad Mahdi Rezaei* (D, Shahrokh Shojaeian and Rasoul Rouhollahi
}

*Correspondence:

mm.rezaei@iaukhsh.ac.ir

Department of Electrical

Engineering, Khomeinishahr

Branch, Islamic Azad

University, Isfahan, Iran

\begin{abstract}
Due to the development of power electronic devices, the DC microgrids are competing AC microgrids, and even in some areas, such as efficiency, reliability, stability, DC microgrids are superior. In spite of mentioned advantages, the main technical challenge related to operation of the DC microgrids is to provide a fast and stable voltage regulation. In this paper, a robust control structure is proposed for multi-bus DC microgrids. Adopting master-slave control strategy, an adaptive voltage control scheme is proposed to robustly maintain the master unit voltage at the nominal value. In addition, an adaptive current controller is designed to robustly regulate the current of all the DG units in the grid-connected mode, as well as the slave units in the islanded mode of operation. All of the controllers are designed based on local measurements and are independent with respect to parameters, dynamic, and topology of the DCMG loads. The control scheme is shown to be stable and robust subject to parametric uncertainties and various types of disturbances. The consistent and effectiveness of the proposed control scheme is demonstrated through simulation studies in MATLAB ${ }^{\circledR}$ software environment.
\end{abstract}

Keywords: DC microgrid, DC distributed generation, Master/slave structure, Lyapunov control theory

\section{Introduction}

Driven by remarkable concerns about the environmental issues and limited energy sources, the penetration of the distributed energy resources (DERs) and distributed generation (DG) units is on the rapid rise [1,2]. Microgrids are small-scale distribution networks that provide requirements for integrating the DER-based DG units and loads, and improve the stability, reliability, and efficiency of power supply [3, 4]. Microgrids can be classified in alternative current $(\mathrm{AC})$ and direct current (DC) types. Although the AC microgrids (ACMGs) are more popular, the DC microgrids (DCMGs) have many advantages compared to ACMGs. The DCMGs have higher stability, reliability, and efficiency, while having no frequency, synchronization, stability, harmonics, power quality, and reactive power issues [5]. In addition, most of the DERs are either naturally in DC form, such as photovoltaic and fuel cells, or converted to DC form, such as wind energy conversion systems. Moreover, most of domestic and commercial loads, such as electronical or digital appliances, are inherently in DC form, and some of these loads that work with $\mathrm{AC}$ power, such as home and kitchen electrical appliances, can also operate with DC

(c) The Author(s) 2020. This article is licensed under a Creative Commons Attribution 4.0 International License, which permits use, sharing, adaptation, distribution and reproduction in any medium or format, as long as you give appropriate credit to the original author(s) and the source, provide a link to the Creative Commons licence, and indicate if changes were made. The images or other third party material in this article are included in the article's Creative Commons licence, unless indicated otherwise in a credit line to the material. If material is not included in the article's Creative Commons licence and your intended use is not permitted by statutory regulation or exceeds the permitted use, you will need to obtain permission directly from the copyright holder. To view a copy of this licence, visit http://creativeco mmons.org/licenses/by/4.0/. 
power. Currently, DCMGs have been widely deployed in data centres, communication systems, electric vehicles, traction systems, aircrafts, submarines, islands and villages, and it is expected to become more widespread [6].

In spite of many benefits, the DCMGs present some technical challenges. The main issue related to operation of DCMGs is to provide a fast and stable voltage regulation [6]. So far, different methods have been reported in the literature, which can fall in Droop control method and master-slave (MS) control method categories. In the Droop control method, the load current is shared between DC distributed generation (DCDG) units based on their droop characteristics, and all the DCDG units participate in regulating the DCMG voltage. In the MS control method, a DCDG unit is designated to be responsible to voltage control as a master unit, and other DCDG units inject pre-specified amount of currents to DCMG as slave units. Consequently, enhancement of steady-state and dynamic behaviour and disturbance rejection performance of DCMG in both the Droop and MS methods is strongly depended on the stability and robustness of applied voltage control scheme [7].

Several methods for voltage control of DCMGs have been reported in the literature. Among them, conventional linear control techniques are still deployed. However, the effectiveness of these techniques is depended on linearization of system and operating point. Moreover, large uncertainties and disturbances strongly affect the performance of control system [8]. Nonlinear control techniques are other options which can overcome the drawbacks of linear methods and exhibit higher performance. Most of nonlinear controllers are designed based on exact knowledge of system parameters. Therefore, the robust performance of control systems should be investigated against parametric uncertainties and disturbances [8]. In [7, 9], fractional order sliding mode controller has used to enhance the current control performance of DCDGs in an islanded DCMG. Model predictive control scheme [10, 11], projection-algorithm-based sliding mode control [12], and $H_{\infty}$ robust control scheme $[13,14]$ are used to enhance the stability and robustness of DCMGs. In [15], the voltage balance of a bipolar DCMG is improved by using a communication based centralized controller. A distributed secondary controller and a remote load current measurement scheme are used in [16, 17], respectively, to mitigate the voltage steady state error in DCMGs. In order to enhance the stability of the DCMG systems in the presence of constant power loads, some Lyapunov functionbased control methods have been presented in [18-21]. In [22], a cascade structure is presented to voltage control of a DCDG. The adopted control structure in [22] is based on linear robust method and contains an inner control loop that estimates uncertainties and disturbances, and an outer control loop that tracks the desired control trajectory. An optimal control has been used in [23] to voltage control of a DCDG, which is robust with respect to load uncertainties. However, the control methods presented in [7, 9-22] are designed based on online measurement of instantaneous load current and can be applicable only for local loads. In case of non-local loads, the measurement of the instantaneous load current is relying on high bandwidth communication links between each non-local load and controllers, which can make the control method impractical $[12,16]$.

The main contribution of this paper is to propose (1) an adaptive current controller to force all of the DCDG units in the grid-connected mode, as well as the slave units in 
islanded mode, to regulate their current at respective pre-specified amounts; (2) a cascadestructure adaptive voltage control, adopting MS control strategy, to robustly force the output voltage of master unit to track pre-defined reference value. All of the controllers are designed based on local measurements and are independent with respect to parameters, dynamic, and topology of the DCMG loads. The proposed control scheme in this paper is indicated to be stable and robust with respect to parametric uncertainties and various types of disturbances. The consistent and effectiveness of the presented control scheme is confirmed through simulation studies in MATLAB ${ }^{\circledR}$ software environment.

This paper is organised as follows. The DCMG under consideration is briefly described in Sect. 2. Section 2.2 presents the mathematical modelling of a DCDG unit. Section 2.3 is dedicated to the proposed control scheme. Section 3 presents the simulation results, and Sect. 4 concludes this paper.

\section{Methods}

\section{System description}

Figure 1 shows the understudy DCMG including two DC distributed generation (DCDG) units, a multi-bus DC network, and cluster of local and common loads. Each DCDG unit is modelled by a DC voltage source and a DC-DC Buck-Boost converter (BBC). The point of common coupling (PCC) bus can be connected to the main DC grid through a circuit breaker. Depending on the status of the circuit breaker, the DCMG either can operates in grid-connected mode, or can autonomously operates in islanded mode. The parameters of the DCMG and DCDGs are given in "Appendix" [24].

\section{Modelling of a DCDG unit}

Figure 2 shows a BBC-based DCDG unit [25]. Taking into account the parameters in the nominal conditions and neglecting the discontinuous conduction mode, the averaged dynamics model of the $\mathrm{BBC}$ can be expressed as:

$$
\begin{aligned}
& \frac{\mathrm{d}}{\mathrm{d} t} i=\theta_{1} \delta-\theta_{2}(1-\delta) v-\theta_{3} i \\
& \frac{\mathrm{d}}{\mathrm{d} t}=\theta_{4}(1-\delta) i-\theta_{4} i_{\mathrm{o}}
\end{aligned}
$$

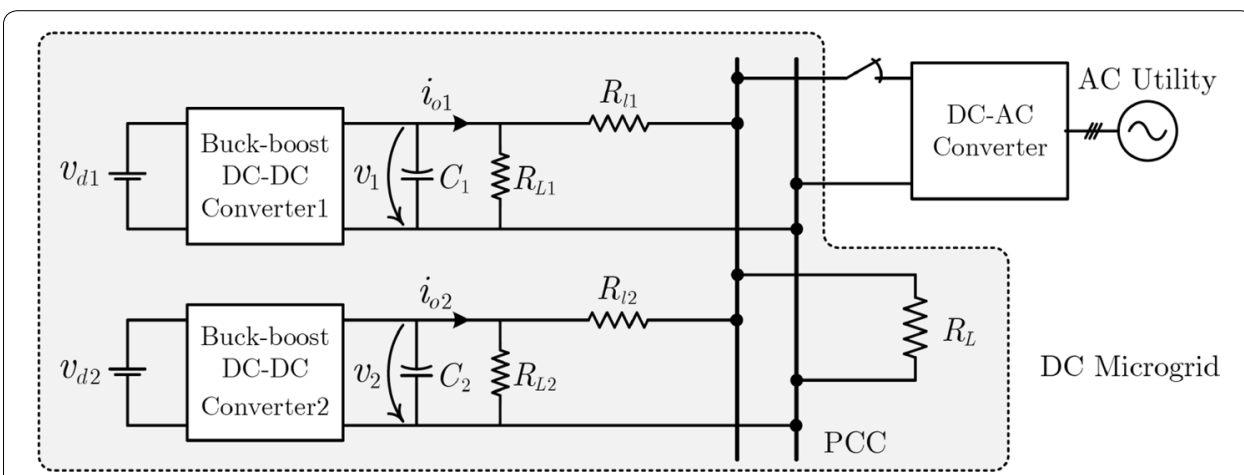

Fig. 1 Schematic diagram of the microgrid under consideration 


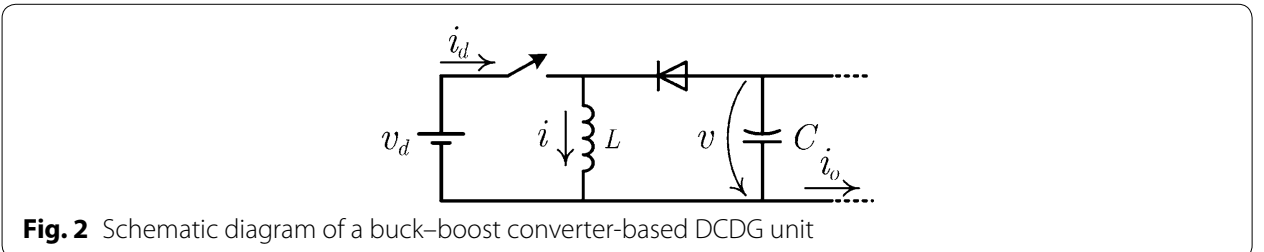

where the state variables $i$ and $v$ are the average current and voltage of the BBC inductor and capacitor, respectively, $i_{\mathrm{o}}$ is the output current of the BBC that is considered as a measurable external disturbance, $\delta$ is the duty cycle of $\mathrm{BBC}$ switch, and

$$
\theta_{1}=\frac{v_{d}}{L}, \quad \theta_{2}=\frac{1}{L}, \quad \theta_{3}=\frac{R}{L}, \quad \theta_{4}=\frac{1}{C}
$$

are the $\mathrm{BBC}$ parameters in the nominal conditions. If the parameters $\theta_{1}-\theta_{4}$ deviate from their nominal values, the BBC state equations can be modified as

$$
\begin{aligned}
& \frac{\mathrm{d}}{\mathrm{d} t} i=\theta_{1} \delta-\theta_{2}(1-\delta) v-\theta_{3} i+\xi_{\mathrm{i}} \\
& \frac{\mathrm{d}}{\mathrm{d} t} v=\theta_{4}(1-\delta) i-\theta_{4} i_{\mathrm{o}}+\xi_{\mathrm{v}}
\end{aligned}
$$

where $\xi_{\mathrm{i}}$ and $\xi_{\mathrm{v}}$ are the lumped uncertainties imposed on system dynamics containing parametric uncertainties and system dynamic disturbances.

\section{Control strategy}

In the grid-connected mode, all of the DCDG units operate in the current control mode. Therefore, both the DCDG1 and DCDG2 units are equipped with a designed adaptive current controller which regulates their current at pre-specified values. Adopting MS control strategy in the islanded mode, while DCDG2 operates in current controlled mode, as a slave unit, fulfilling the voltage control of the DCMG is deputed to DCDG1 as a master unit. Therefore, an adaptive voltage controller is designed in this paper that mounts on the inner current controller in a cascade structure, to force the voltage of DCMG to track predefined trajectory. In order to enhance the dynamic response, reference tracking performances, and robustness of the proposed control scheme, all of the controllers are adaptive designed in such a way that the lumped uncertainties imposed the system dynamics are estimated based on Lyapunov control theory. In the following subsections, the process of designing controllers is presented in details.

\section{Current controller}

The basis of both the master and slave controllers in the proposed control strategy is an adaptive current controller. Letting

$$
e_{\mathrm{i}}=i^{\mathrm{ref}}-i
$$

be the reference current tracking error, and 


$$
\tilde{\xi}_{\mathrm{i}}=\hat{\xi}_{\mathrm{i}}-\xi_{\mathrm{i}}
$$

be the error between $\xi_{\text {i }}$ and its estimated value $\hat{\xi}_{\mathrm{i}}$, then, to generate an adaptive control law, the following positive-definite Lyapunov function is selected

$$
V_{\mathrm{i}}=\frac{1}{2} e_{\mathrm{i}}^{2}+\frac{1}{2} \gamma_{\mathrm{i}} \tilde{\xi}_{\mathrm{i}}^{2}
$$

where $\gamma_{\mathrm{i}}>0$ is an estimation gain. The time derivate of $V_{\mathrm{i}}$ can be expressed as

$$
\frac{\mathrm{d}}{\mathrm{d} t} V_{\mathrm{i}}=e_{\mathrm{i}} \frac{\mathrm{d}}{\mathrm{d} t} e_{\mathrm{i}}+\gamma_{\mathrm{i}} \tilde{\xi}_{\mathrm{i}} \frac{\mathrm{d}}{\mathrm{d} t} \tilde{\xi}_{\mathrm{i}}
$$

Using (6), (7), and (4), it can be obtain that

$$
\frac{\mathrm{d}}{\mathrm{d} t} V_{\mathrm{i}}=e_{\mathrm{i}}\left(\frac{\mathrm{d}}{\mathrm{d} t} i^{\mathrm{ref}}-\theta_{1} \delta+\theta_{2}(1-\delta) v+\theta_{3} i-\xi_{\mathrm{i}}\right)+\gamma_{\mathrm{i}} \tilde{\xi}_{\mathrm{i}} \mathrm{d} t \hat{\xi}_{\mathrm{i}}
$$

By cancelling the second term in right side of (10), the estimation law can be determined as [4]:

$$
\frac{\mathrm{d}}{\mathrm{d} t} \hat{\xi}_{\mathrm{i}}=-\gamma_{\mathrm{i}}^{-1} e_{\mathrm{i}}
$$

Considering (11), $\frac{\mathrm{d}}{\mathrm{d} t} V_{\mathrm{i}}$ can be given by

$$
\frac{\mathrm{d}}{\mathrm{d} t} V_{\mathrm{i}}=e_{\mathrm{i}}\left(\frac{\mathrm{d}}{\mathrm{d} t} i^{\mathrm{ref}}-\theta_{1} \delta+\theta_{2}(1-\delta) v+\theta_{3} i-\hat{\xi_{\mathrm{i}}}\right)
$$

If the control input $\delta$ is selected as

$$
\delta=\left(\theta_{1}+\theta_{2} v\right)^{-1}\left(\frac{\mathrm{d}}{\mathrm{d} t} i^{\mathrm{ref}}+\theta_{3} i-\hat{\xi}_{\mathrm{i}}+\theta_{2}+k_{\mathrm{i}} e_{\mathrm{i}}\right)
$$

where $k_{\mathrm{i}}>0$ is a control gain, then, it can be obtain that

$$
\frac{\mathrm{d}}{\mathrm{d} t} V_{\mathrm{i}}=-k_{\mathrm{i}} e_{\mathrm{i}}^{2}<0
$$

that is a negative-definite function and based on Barballat's Lemma [26], it can be conclude that the current controller system is asymptotically stable.

\section{Voltage controller}

The main control objective for master unit is to force the voltage of DCMG to remain at its nominal value. Letting

$$
e_{\mathrm{v}}=v^{\mathrm{ref}}-v
$$

be the reference voltage tracking error, and

$$
\tilde{\xi}_{\mathrm{v}}=\hat{\xi}_{\mathrm{v}}-\xi_{\mathrm{v}}
$$

be the estimation error, where $\xi_{\mathrm{v}}$ is estimated value of $\hat{\xi}_{\mathrm{v}}$, a positive-definite Lyapunov function can be chosen as:

$$
V_{\mathrm{v}}=\frac{1}{2} e_{\mathrm{v}}^{2}+\frac{1}{2} \gamma_{\mathrm{v}} \tilde{\xi}_{\mathrm{v}}^{2}
$$


where $\gamma_{\mathrm{v}}>0$ is an estimation gain. Differentiating $V_{\mathrm{v}}$ with respect to time gives

$$
\frac{\mathrm{d}}{\mathrm{d} t} V_{\mathrm{v}}=e_{\mathrm{v}} \frac{\mathrm{d}}{\mathrm{d} t} e_{\mathrm{v}}+\gamma_{\mathrm{v}} \tilde{\xi}_{\mathrm{v}} \frac{\mathrm{d}}{\mathrm{d} t} \tilde{\xi}_{\mathrm{v}}
$$

Considering (15), (16) and (5), it can be obtained that

$$
\frac{\mathrm{d}}{\mathrm{d} t} V_{\mathrm{v}}=e_{\mathrm{v}}\left(\frac{\mathrm{d}}{\mathrm{d} t} t^{\mathrm{ref}}-\theta_{4}(1-\delta) i+\theta_{4} i_{\mathrm{o}}-\xi_{\mathrm{v}}\right)+\gamma_{\mathrm{v}} \tilde{\xi}_{\mathrm{v}} \frac{\mathrm{d}}{\mathrm{d} t} \hat{\xi}_{\mathrm{v}}
$$

If the adaption law is chosen as [4]:

$$
\frac{\mathrm{d}}{\mathrm{d} t} \hat{\xi}_{\mathrm{v}}=-\gamma_{\mathrm{v}}^{-1} e_{\mathrm{v}}
$$

$\frac{\mathrm{d}}{\mathrm{d} t} V_{\mathrm{v}}$ can be reduced to

$$
\frac{\mathrm{d}}{\mathrm{d} t} V_{\mathrm{v}}=e_{\mathrm{v}}\left(\frac{\mathrm{d}}{\mathrm{d} t} \nu^{\mathrm{ref}}-\theta_{4}(1-\delta) i+\theta_{4} i_{\mathrm{o}}-\hat{\xi_{\mathrm{v}}}\right)
$$

With the following control law

$$
i^{\text {ref }}=(1-\delta)^{-1}\left(i_{\mathrm{o}}+\theta_{4}^{-1}\left\{\frac{\mathrm{d}}{\mathrm{d} t} v^{\mathrm{ref}}-\hat{\xi_{\mathrm{v}}}+k_{\mathrm{v}} e_{\mathrm{v}}\right\}\right)
$$

where $k_{\mathrm{v}}>0$ is a control gain, it can be obtain that

$$
\frac{\mathrm{d}}{\mathrm{d} t} V_{\mathrm{v}}=-k_{\mathrm{v}} e_{\mathrm{v}}^{2}<0
$$

Based on Barballat's Lemma [26], it can be conclude that $e_{\mathrm{v}} \rightarrow 0$ asymptotically. While the master unit current controller follows a pre-specified reference current in the gridconnected mode, the current reference in the islanded mode of operation is determined by (22) to force the DCMG voltage to track a pre-defined trajectory. The block diagram of the proposed current and voltage controllers is shown in Fig. 3.

\section{Results and discussion}

In order to demonstrate the effectiveness of proposed control structure, the DCMG study system depicted in Fig. 1 has been simulated in MATLAB ${ }^{\circledR}$ software environment. The simulations are executed using a PC with Intel ${ }^{\circledR} \mathrm{Core}^{\mathrm{TM}} \mathrm{i} 7 \mathrm{CPU}$ at $2.5 \mathrm{GHz}$, 8 GB RAM, and 64-bit Windows 10 operating system. The parameters of understudy system are given in "Appendix" [24]. In this paper, the performance of the proposed control structure (denoted as "Proposed") is compared with a PI-based control structure (denoted as "PIBC") in which the current of all the DCDG units in the grid-connected mode and the voltage of the master unit in the islanded mode are controlled based on PI controllers. It is worth noting that in order to make a fair comparison, both the proposed

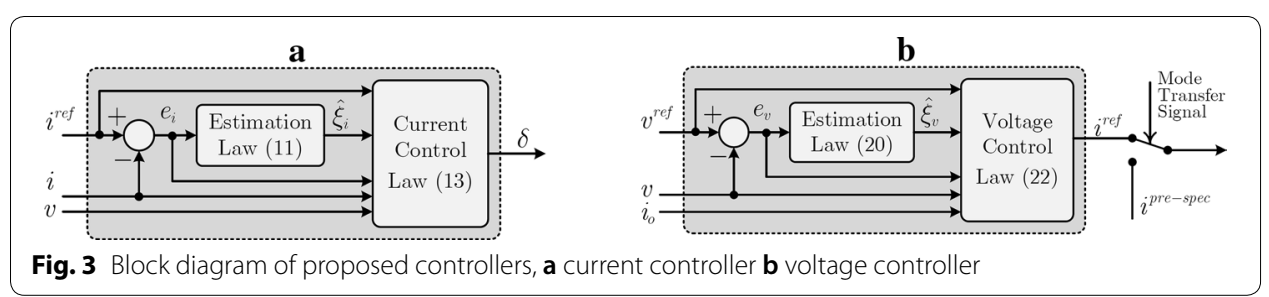


and PIBC control structures are designed and adjusted to show the best performance. In the simulation studies, the performance of the proposed and PIBC control structures is evaluated in both the grid-connected and islanded mode of operations. The simulation results and discussions related to DCMG operation modes are presented in the following subsections.

\section{Grid-connected mode of operation}

In the grid-connected mode, the DCMG voltage is dictated by the main DC grid and the role of all the DCDG units is to inject pre-specified currents to the DCMG. In this case study, while the DCDG1 and DCDG2 initially injected their own reference values, which, respectively, are $i_{1}^{\text {ref }}=0.7 \mathrm{~A}$, and $i_{2}^{\text {ref }}=0.5 \mathrm{~A}$, both the current references are exponentially increased to $1 \mathrm{~A}$ at $t=0.2 \mathrm{~s}$, with $0.01 \mathrm{~s}$ time constant. Subsequently, the robustness of proposed control structure is evaluated against sudden accidental increase of main grid voltage at $t=0.4 \mathrm{~s}$, as an external disturbance. To confirm the robust performance of presented controllers against parametric uncertainties, a $20 \%$ step mismatch is assumed for inductance of both the DCDG units and also capacitance of DCDG2, from $t=0.6 \mathrm{~s}$. The dynamic response of the system to described events is shown in Fig. 4.

Figure $4 \mathrm{a}$ and $\mathrm{b}$ shows the output voltages of DCDG units. As indicated, subsequent to increasing the current references at $t=0.2 \mathrm{~s}$, the output voltages of DCDGs are increased in such a way that more current is injected into the DCMG according to the tie lines between the DCDGs and the PCC bus. In addition, since the system voltage in

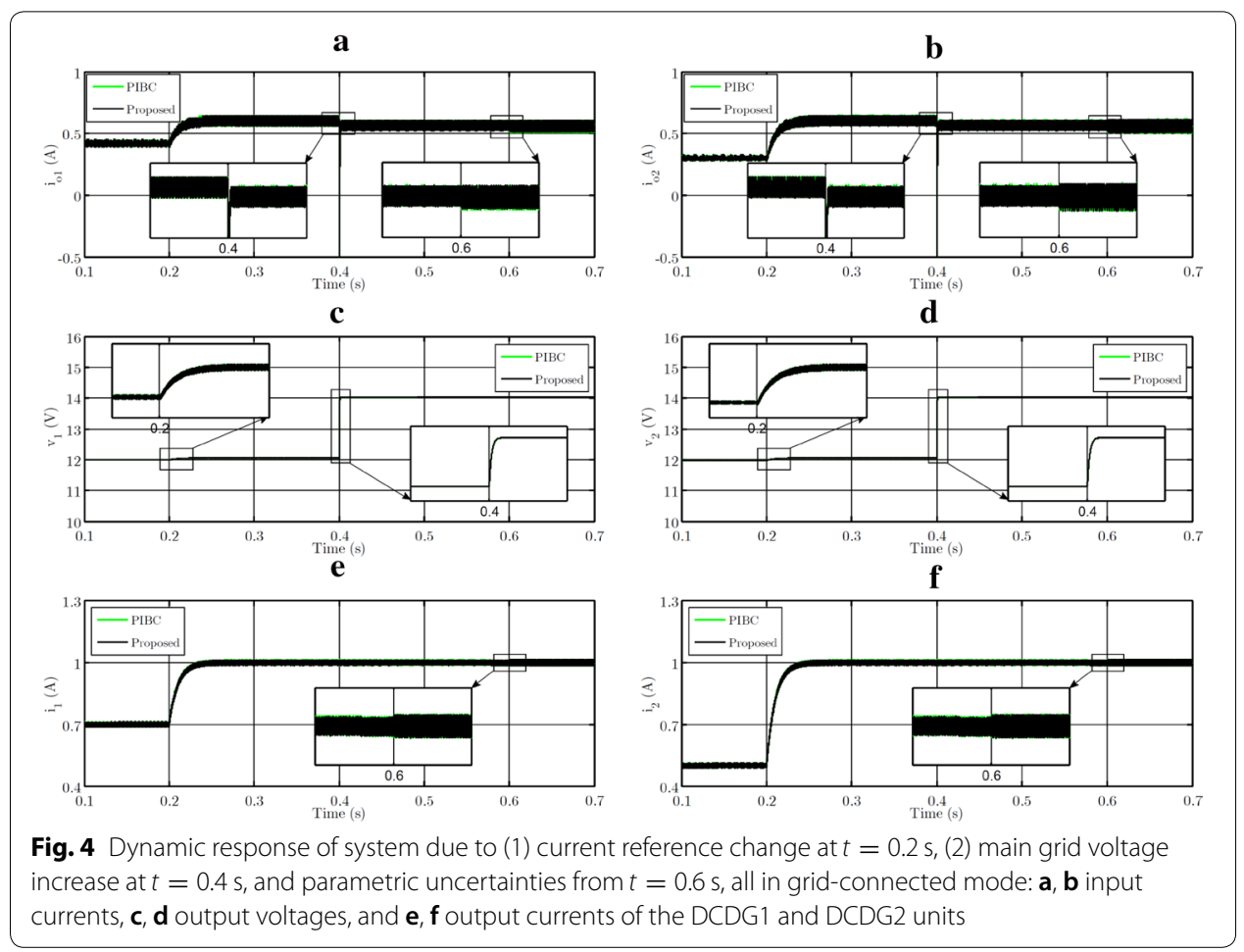


the connected mode is dictated by the main grid, with the sudden change in the main grid voltage at $t=0.4 \mathrm{~s}$, the output voltages of both DCDGs are suddenly increased.

Figure $4 \mathrm{c}$ and $\mathrm{d}$ indicates the output currents of DCDG units. It can be seen that as the current of the converters increases at $t=0.2 \mathrm{~s}$, the output currents of the DCDGs also are exponentially increased. Moreover, due to the presence of parallel capacitors in the DCDGs, after the sudden change in the voltage of the main DC grid at $t=0.4 \mathrm{~s}$, considerable transients are observed in the output currents of the DCDGs. Figure $4 a-d$ indicates that the output voltages and currents of DCDGs exhibit no observable transient or variation due to the occurred parametric uncertainties at $t=0.6 \mathrm{~s}$. It is worth noting that in the grid-connected mode of operation, the output voltages and currents of DCDGs are treated as external disturbances for the converter current controllers.

Figure $4 \mathrm{e}$ and $\mathrm{f}$ shows the converter currents. These figures indicate that subsequent to reference command variations, the presented current controllers properly track their desirable trajectories. In addition, it can be seen from Fig. $4 \mathrm{e}$ and $\mathrm{f}$ that subsequent to the grid voltage disturbance at $t=0.4 \mathrm{~s}$ and the parametric uncertainties at $t=0.6 \mathrm{~s}$, the current controllers exhibit a strongly robust performance without any observable transients. It is worth noting that the high-frequency ripples observed in Fig. $4 \mathrm{a}-\mathrm{f}$ are due to switching harmonics.

This case study confirms the robustness of both the proposed and PIBC control structures in tracking the reference commands and maintaining the stability of the control system despite the parametric uncertainties and external disturbances.

\section{Islanded mode of operation}

As mentioned before, the DCDG1 is designated to fulfil the voltage control of DCMG in the islanded mode, as a master unit. In both the proposed and PIBC control structures, the master unit has been equipped with a cascade voltage control such that the reference signal of the current controller is determined by an outer voltage controller loop.

In this case study, while the voltage reference of master unit and the current reference of slave unit are initially set to $12 \mathrm{~V}$ and $0.5 \mathrm{~A}$, respectively, the current references of slave unit are exponentially increased to $1 \mathrm{~A}$ at $t=0.2 \mathrm{~s}$, with $0.01 \mathrm{~s}$ time constant. Then, in order to investigate the robust performance of the proposed voltage controller with respect to load disturbances and parametric uncertainties, at first, a sinusoidally oscillation with an amplitude of $25 \%$ of nominal value and frequency of $20 \mathrm{~Hz}$ is assumed for the common load resistance from $t=0.4 \mathrm{~s}$, and secondly, a $20 \%$ step mismatch is assumed for the inductance of both the DCDG units and the capacitance of DCDG2, from $t=0.6 \mathrm{~s}$. Figure 5 shows the dynamic response of the system with respect to described scenario.

Figure $5 \mathrm{a}$ and $\mathrm{b}$ shows the output currents of the DCDGs. It can be seen from Fig. $5 \mathrm{~b}$ that simultaneously with the increase in the converter current of the slave unit at $t=0.2 \mathrm{~s}$, its output current has also increased exponentially. In addition, due to the fact that the load of the system has not changed yet, the output current of the master unit is automatically reduced to maintain the balance between production and consumption in the islanded DCMG, as indicated in Fig. 5b. Moreover, as the common load oscillates from $t=0.4 \mathrm{~s}$, while there are no significant oscillations in the output current of the 


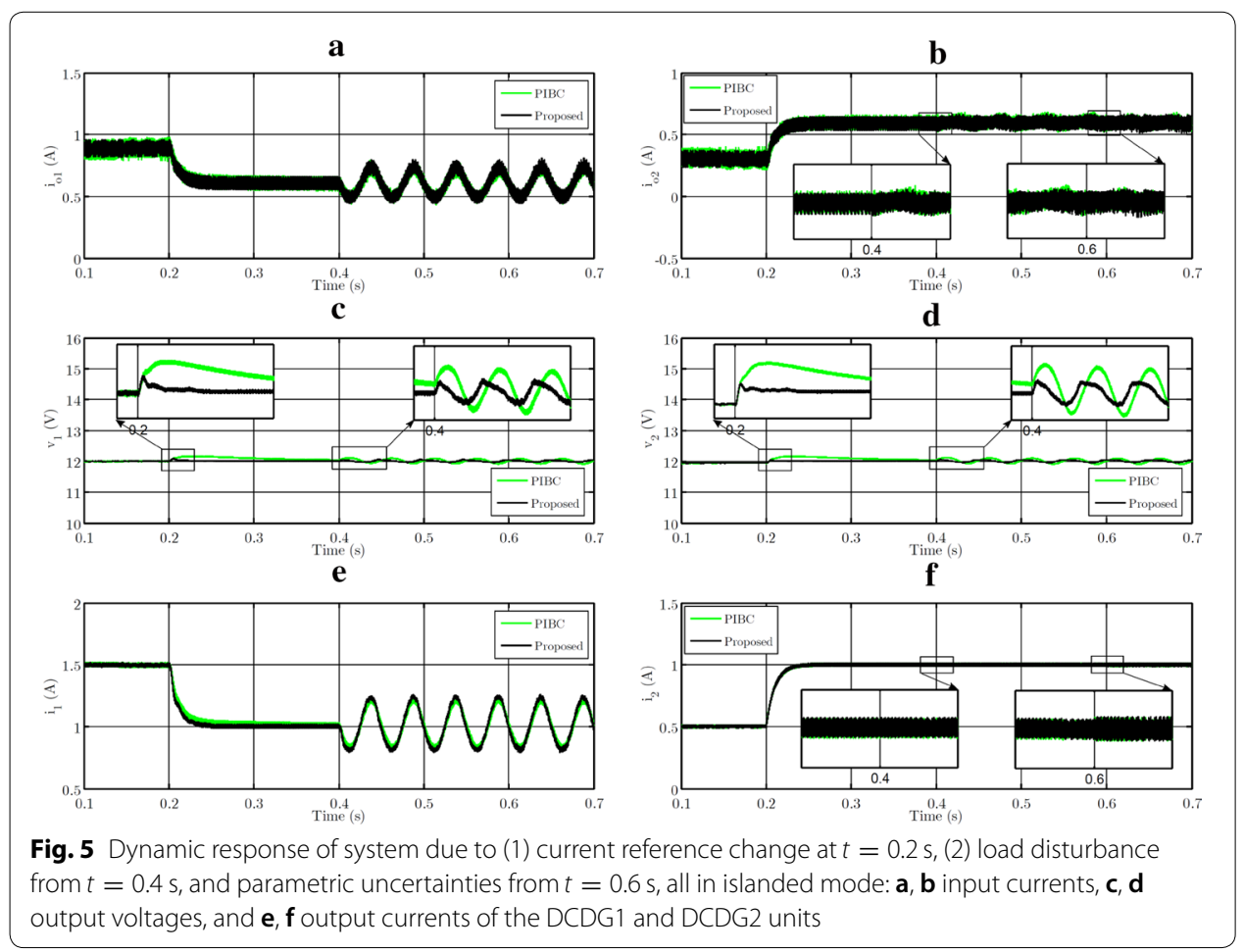

slave unit, the output current of the master unit begins to oscillate in response to the load demand. Moreover, it can be seen that because the network operates in islanded mode, the switching-based high-frequency ripples observed in Fig. $5 \mathrm{a}$ and $\mathrm{b}$ are greater than in Fig. $4 \mathrm{a}$ and $\mathrm{b}$.

Figure $5 \mathrm{c}$ and $\mathrm{d}$ indicates the output voltages of the DCDGs. As shown, after changing the converter current of the slave unit at $t=0.2$, the output voltage of the converters in the proposed structure has followed its reference value, after an acceptable transient state. However, the output voltages of the DCDG units in the PIBC structure have reached its reference value after a longer transient state. It may be thought that increasing the voltage control gains in the PIBC structure can reduce the voltage settling time, but our efforts have shown that increasing the mentioned gains causes the instability of the nonlinear autonomous system in the islanded mode. Figure $5 \mathrm{c}$ and $\mathrm{d}$ shows that simultaneous with common load oscillations from $t=0.4$, although the output voltage of the converters oscillates due to the oscillations of the output current of the master unit, they continue to follow their reference values. As can be seen, the amplitude of the voltage oscillations in the PIBC structure is greater than the proposed structure. The reason for this is that the PI controllers do not perform well in tracking the oscillating references.

Figure 5e and $\mathrm{f}$ shows the converter current of both the master and slave units. As shown in Fig. 5f, the slave unit robustly tracks its reference current trajectory, even after the common load disturbances and parametric uncertainties. In addition, Fig. 5e shows that the current variations of master unit automatically are in accordance with the slave unit current variation and load disturbances in such a way that, the master unit can track its voltage reference signal. 
This case study demonstrates the robustness and the stability of the proposed structure in regulating the voltage of the DCMG against fast increment of the slave unit generation, common load disturbances, and parametric uncertainties, in islanded mode of operation.

\section{Conclusions}

In this paper, adopting master-slave control strategy, an adaptive control scheme is proposed based on Lyapunov theory for multi-bus multi-DG DC microgrids. In the proposed control structure, an adaptive current controller is designed for all DCDG units to regulate the current of each of units at their pre-specified value, in the gridconnected mode of operation. In addition, an adaptive voltage controller is designed for master DCDG unit in cascade with its current controller to fulfil the voltage control of the DC microgrid in islanded mode, by robustly forcing the output voltage of the master unit to track a pre-defined reference value. The proposed control scheme has been designed based on local measurements and independent with respect to parameters, dynamic, and topology of the DC microgrid loads. The lumped uncertainties imposed on system dynamics has been estimated which enhance the system robustness with respect to unwanted modelling and measurement errors and parametric uncertainties. The performance of the proposed control structure is compared with a fairly tuned PI-based control scheme in which the current of all the DCDG units in the grid-connected mode and the voltage of the master unit in the islanded mode are controlled based on PI controllers. The validity and effectiveness of the proposed control structure have been confirmed through simulation studies in MATLAB ${ }^{\circledR}$ software environment. The presented results demonstrate that the proposed control scheme is robust and stable against parametric uncertainties and various types of external disturbances.

\section{List of symbols}

Abbreviations

AC: Alternative current; ACMG: AC microgrid; BBC: Buck-boost converter; DC: Direct current; DCDG: DC distributed generation; DCMG: DC microgrid; DG: Distributed generation; DER: Distributed energy resource; MG: Microgrid; PCC: Point of common coupling.

DCDG variables

$i$ : Average inductor current; $v$ : Average capacitor voltage; $\delta$ : Duty cycle of switch; $i_{0}$ : Output current; $C_{1}, C_{2}$ : DCDG's output capacitors; $\theta_{1}-\theta_{4}$ : Parameters of BBC in the nominal conditions; $\xi_{i}, \xi_{v}$ : Lumped uncertainties imposed on system dynamics.

DCMG variables

$R_{L 1}, R_{L 2}$ : Local load resistors; $R_{11}, R_{12}$ : Connecting cable resistors; $R_{L}$ : Non-local load resistor.

Control system variables

$V_{i}, V_{v}$ : Lyapunov functions; $e_{i}, e_{v}$ :Tracking errors; $\hat{\xi}_{i}, \hat{\xi}_{v}$ : Estimated values of $\xi_{i}, \xi_{v} ; \tilde{\xi}_{i}, \tilde{\xi}_{v}$ : Uncertainty

estimation errors; $\gamma_{1}, \gamma_{v}$ : Estimation gains; $k_{i}, k_{v}$ : Control gains.

Subscripts

i: Related to current controller; v: Related to voltage controller. 


\section{Superscripts}

$\wedge$ : Estimated value of uncertainties; : Uncertainty estimation error; ref: Reference value.

\section{Acknowledgements}

Not applicable. We do not have anyone to acknowledge.

\section{Authors' contributions}

MMR conceived of the presented idea. MMR and SS developed the theory and performed the computations. MMR and RR verified the analytical methods. MMR encouraged RR to investigate and supervised the findings of this work. All authors discussed the results and contributed to the final manuscript. All authors read and approved the final manuscript.

\section{Funding}

This research received no specific grant from any funding agency in the public, commercial, or not-for-profit sectors.

Availability of data and materials

Not applicable. Our manuscript does not contain any data.

\section{Competing interests}

The authors declare that they have no competing interests.

\section{Appendix}

The parameters of understudy system are given as:

DCDGs and DCMG: $v_{g}=12 \mathrm{~V}, v_{d 1,2}=18 \mathrm{~V}, R_{1,2}=0.1 \Omega, L_{1,2}=16 \mu \mathrm{H}, C_{1,2}=470 \mu \mathrm{F}$, $R_{L}=20 \Omega, R_{L 1,2}=40 \Omega, R_{l 1,2}=0.1 \Omega, R_{g}=0.1 \Omega$.

Control structures: $k_{\mathrm{i} 1,2}=1000, k_{\mathrm{v}}=100 \mu, \gamma_{\mathrm{i} 1,2}=0.01, \gamma_{\mathrm{v}}=0.01 \mu, k p_{\mathrm{i} 1,2}=1000$, $k i_{\mathrm{i} 1,2}=50, k p_{\mathrm{v}}=1, k i_{\mathrm{v}}=10$.

Received: 11 February 2020 Accepted: 28 April 2020

Published online: 03 June 2020

\section{References}

1. Di Nucci MR, Russolillo D (2017) The fuzzy Europeanization of the Italian renewable energy policy: the paradox of meeting targets without strategic capacity. In: A Guide to EU Renewable Energy Policy. Edward Elgar Publishing

2. Frank S, Bottcher H, Gusti M, Havlík P, Klaassen G, Kindermann G, Obersteiner M (2016) Dynamics of the land use, land use change, and forestry sink in the European Union: the impacts of energy and climate targets for 2030. Clim Change 138(1-2):253-66

3. Rezaei MM, Soltani J (2015) A robust control strategy for a grid-connected multi-bus microgrid under unbalanced load conditions. Int J Electr Power Energy Syst 1(71):68-76

4. Rezaei MM, Soltani J (2015) Robust control of an islanded multi-bus microgrid based on input-output feedback linearisation and sliding mode control. IET Gener Transm Distrib 9(15):2447-54

5. Mortezapour V, Lesani H (2017) Hybrid AC/DC microgrids: a generalized approach for autonomous droop-based primary control in islanded operations. Int J Electr Power Energy Syst 1(93):109-18

6. Shuai Z, Fang J, Ning F, Shen ZJ (2018) Hierarchical structure and bus voltage control of DC microgrid. Renew Sustain Energy Rev 82:3670-3682

7. Asghar M, Khattak A, Rafiq MM (2017) Comparison of integer and fractional order robust controllers for DC/DC converter feeding constant power load in a DC microgrid. Sustain Energy Grids Netw 1(12):1-9

8. Oucheriah S (2015) Robust nonlinear adaptive control of a DC-DC boost converter with uncertain parameters. Int J Innov Comput Inf Control 11(3):893-902

9. Farsizadeh H, Gheisarnejad M, Mosayebi M, Rafiei M, Khooban MH (2019) An intelligent and fast controller for DC/ DC converter feeding CPL in a DC microgrid. leee Transactions on Circuits and Systems li: Express Briefs

10. Xiao S, Shadmand MB, Balog RS (2017) Model predictive control of multi-string PV systems with battery back-up in a community dc microgrid. In: Applied power electronics conference and exposition (APEC). IEEE, pp 1284-1290

11. Chen L, Gao F, Shen K, Wang Z, Tarisciotti L, Wheeler P, Dragicevic T (2020) Predictive Control based DC Microgrid Stabilization with the Dual Active Bridge Converter. In: IEEE Transactions on Industrial Electronics

12. Vu TV, Perkins D, Diaz F, Gonsoulin D, Edrington CS, El-Mezyani T (2017) Robust adaptive droop control for DC microgrids. Electric Power Syst Res 1(146):95-106 
13. Dou C, Yue D, Guerrero JM, Xie X, Hu S (2017) Multiagent system-based distributed coordinated control for radial DC microgrid considering transmission time delays. IEEE Trans Smart Grid 8(5):2370-81

14. Zhou J, Xu Y, Sun H, Wang L, Chow MY (2019) Distributed event-triggered $H_{\infty}$ consensus based current sharing control of DC microgrids considering uncertainties. In: IEEE Transactions on Industrial Informatics

15. Tavakoli SD, Mahdavyfakhr M, Hamzeh M, Sheshyekani K, Afjei E (2017) A unified control strategy for power sharing and voltage balancing in bipolar DC microgrids. Sustain Energy Grids Netw 1(11):58-68

16. Zhao J, Dorfler F (2015) Distributed control and optimization in DC microgrids. Automatica 1(61):18-26

17. Yang N, Paire D, Gao F, Miraoui A, Liu W (2015) Compensation of droop control using common load condition in DC microgrids to improve voltage regulation and load sharing. Int J Electr Power Energy Syst 1(64):752-60

18. Hossain E, Perez R, Padmanaban S, Mihet-Popa L, Blaabjerg F, Ramachandaramurthy VK (2017) Sliding mode controller and Lyapunov redesign controller to improve microgrid stability: a comparative analysis with CPL power variation. Energies 10(12):1959

19. Armghan $H$, Yang M, Wang MQ, Ali N, Armghan A (2020) Nonlinear integral backstepping based control of a DC microgrid with renewable generation and energy storage systems. Int J Electr Power Energy Syst 1(117):105613

20. Hossain E, Perez R, Padmanaban S, Siano P (2017) Investigation on the development of a sliding mode controller for constant power loads in microgrids. Energies 10(8):1086

21. Hossain E, Perez R, Nasiri A, Bayindir R (2017) Development of lyapunov redesign controller for microgrids with constant power loads. Renew Energy Focus 19:49-62

22. Aharon I, Shmilovitz D, Kuperman A (2017) Robust output voltage control of multimode non-inverting DC-DC converter. Int J Control 90(1):110-20

23. Baranwal M, Salapaka SM, Salapaka MV (2016) Robust decentralized voltage control of dc-dc converters with applications to power sharing and ripple sharing. In: American control conference (ACC), 2016. IEEE, pp 7444-7449

24. Sira-Ramirez HJ, Silva-Ortigoza R (2006) Control design techniques in power electronics devices. Springer, Berlin

25. Mohan N, Undeland TM (2007) Power electronics: converters, applications, and design. Wiley, New York

26. Slotine JJ, Li W (1991) Applied nonlinear control. Prentice hall, Englewood Cliffs, NJ

\section{Publisher's Note}

Springer Nature remains neutral with regard to jurisdictional claims in published maps and institutional affiliations.

\section{Submit your manuscript to a SpringerOpen ${ }^{\circ}$ journal and benefit from:}

- Convenient online submission

- Rigorous peer review

- Open access: articles freely available online

- High visibility within the field

- Retaining the copyright to your article

Submit your next manuscript at $\gg$ springeropen.com 